\title{
Using Scientific Activities to improve the Learning Behavior of Disabled Students in Ramkhamhaeng University.
}

\author{
Wanida Chatwirakom ${ }^{1}$
}

\begin{abstract}
This is an experimental research project aiming to study and develop the use of scientific activities as teaching and learning tools to improve hearing impaired students' learning behavior. The research population consisted of handicapped students with inaudibility. The sample population was a group of 14 hearing-impaired students who enrolled at Ramkhamhaeng University's Hua Mak Campus in Bangkok, Thailand. These were students who willingly participated in making scientific picture frames. The data and details were gathered through the use of a checklist to evaluate scientific skills involving scientific picture frames. Then the participating students were interviewed and a thorough observation was made on their learning behaviors when they were engaged in the aforementioned scientific activities. The data collected was then analyzed using a computer software program to present descriptive statistics and arithmetic mean. The findings are as follows: 1. In general, the students engaged in these scientific activities displayed a good level of performance. Seven of them excellently carried out their tasks while there was only one student whose performance was below the standard. 2. Overall, their learning behaviors exhibited were satisfactory. Four students displayed distinctive learning behaviors and three of them displayed unsatisfactory learning behaviors.
\end{abstract}

Keywords, Scientific Activities, Improve the Learning Behavior of Disabled Students คำสำคัญ

\section{Preface}

The development and improvement of the quality of life for students with disabilities (Office of the Council of State, 2007, Page 2) is defined as, the need to rehabilitate persons with disabilities, to support and provide their welfare and benefits and to advocate for disabled persons to be able to live life independently. They should be entitled to their dignity as human beings, and given an opportunity to live normally amongst the general public. People with disabilities should be encouraged to be socially active and participate in social activities.[1] If we are able to better understand their competence and capabilities, the frequently used term "burden" can be then changed to "resource". This is due to the fact that proper education and better understanding can enhance the quality of human beings.

Ramkhamhaeng University is a leading educational institution that readily provides all students an opportunity for equal education. Students have several options in completing their degrees, through self-study or attending classes at the university because Ramkhamhaeng University is an institution that believes in open supplies of knowledge for students. The flexibility allows students to obtain quality university education, when applied with appropriate study plans. Students with disabilities are considered as another 
group of students enrolled at Ramkhamhaeng University, despite certain physical disabilities. They are given the opportunity to graduate just like any students enrolled at the university as long as they follow the guidelines in obtaining success. Through the research conducted by Srisuk Sujirakul (2008, Page 68), it is found out that all students with disabilities at Ramkhamhaeng University have similar demands on recreational activities services on campus.[2] This finding is consistent to the data provided by the Office of the Higher Education Commission (2011, page 17) that particularly suggests a variety of supporting services for disabled students during the transition between secondary and higher education so that they can learn various skills. [3]

It is Ramkhamhaeng University students' nature that many of them do not show up in classes and several students don't have time to attend lectures in classes. (Kesinee Klinsukon and co-authors, 2013, Page 1)[4] And those students are not quite successful in their studies, as expected. However, if the students pay attention to facilities and tools that the university has provided, they should be able to solve such problems, even to students with disabilities. That made the researcher interested in studying the relation between the development of learning behavior among students with disabilities and usage of science-based activities. This is to determine if there is a change in their behavior or not. It is known that to develop and improve the quality of life requires various academic approaches and branches. One that has continuous changes especially in the modern world and society is science which consists of 2 attributes. They are the knowledge and the processes that will enable disabled students to solve problems in life. Then they will have the positive attitude and courage to face the problem rationally as well as have the motivation to work and to survive. This will eventually leads to success in higher education.

The researchers arranged a scientific activity which involved creating photo frames for students with hearing disabilities in order to give them the opportunity to understand scientific processes. They were students who had already studied these before and also the ones who never had the opportunity to fulfil such processes. After participating this activity, they may be interested in other scientific trainings in order to develop other skills and expertise. This should help facilitate higher efficiency and strengthen basic knowledge and development of various scientific skills needed to help pursue a career as an assistant in the laboratory or other professional disciplines they wish to accomplish. The development of learning behavior certainly helps Ramkhamhaeng University students fully aware of rules and directions that will lead to success in education.

\section{Research Objectives}

1. In order for students with disabilities within Ramkhamhaeng University to practice science-based activities.

2. To help adjust the behavior of disabled students at Ramkhamhaeng University through usage of science-based activities.

\section{Scope of Research Research Contents}


The science-based activity of creating photo frames consisted of a total of four phases: preparation for photo coatings, photo/image preparation, coating and decorations. The completion of the entire process takes a total of a 12-hour period.

\section{Population and sample size Population}

The population in this study was hearing impaired students enrolled in Ramkhamhaeng University, Huamak Campus, Bangkok with a total number of 25 persons. Sample Size

The sample used in this study was a group of hearing-impaired students enrolled in Ramkhamhaeng University, Huamak Campus, Bangkok with a total of 14 persons through voluntary participation in the science-based activity: creating photo frames.

Focused Variables

Variables focused in the study were the usage of science-based activity which included photo framing that had a four phases in total : preparation for photo coatings, photo/ image preparation, coating and decorations.

The dependent variable was the learning behavior of the students with disabilities. The details are as follows:

1. Skills in a scientific manner in executing the photo frame activity were evaluated from the actual results with a total of 4 aspects that included: developing a work plan, how they work, expertise in the assigned task, sense of responsibility for the assigned task and public facilities.

2. Learning behavior of students with disabilities that the researches was evaluated through the use of the observation checklist and the questionnaire which focused on the 3 variables: planning, show of perseverance and problem solving skills.

\section{Expected Outcomes}

1. Students with disabilities at Ramkhamhaeng University would be able to use the science-based activity to develop their learning skills and techniques.

2. Students with disabilities at Ramkhamhaeng University would be able to innovate usable items in their daily life (create photo frames using plastic resin)

3. They students would gain information and insights to be used in developing their skills further and then pursue a career in such fields.

\section{Research Tools}

The tools used in this research included

1. Observation checklist in order to evaluate efficiency in creating scientific photo frames. The evaluation was from the actual results in 4 areas which included work plan, work process, efficiency, level of responsibility in the assigned task and public facilities. There were 5 levels of the processes.

2. Questionnaire and observation made on the learning behavior of disabled students who participated in the science-based activity of photo framing. The questionnaire had been devised with general questions about the field of their studies, average 
grades, accumulated credits, and observation checklist to be used towards the learning behavior of disabled students. Evaluation was made on the actual results focusing on the 3 variables: planning, show of perseverance and problem solving skills. There were 5 steps to be considered.

\section{Research Methodology}

The researcher applied various methods in creating, developing and changing the research tools in each area as follows:

1. The observation checklist was created to evaluate the use of creating scientific frames. The steps are as follows:

1.1 Study the process and steps for which the observation checklist could be devised from scientific evaluation manuals, lectures, researches and the internet.

1.2 Study the details and information about creating scientific photo frames from books, documents, and the internet

1.3 Build observation checklist in order to evaluate the usage of science based activities : producing scientific photo frames on the 4 steps that include creation, standard operating procedure, efficiency and sense of responsibility towards the assignment and public facilities. The evaluation was from actual accounts and production of the scientific photo frames in the 4 areas and 5 score levels which included very good, good, fair, needs improvement and change needed

1.4 Send the observation checklist to evaluate the science based activity: developing scientific photo frames to 5 experts in order for them to investigate and check its accuracy with the use of the Index of Congruence (IOC). The finding was the IOC ranged between the values of $0.80-1.00$

1.5 Apply the observation checklist with the actual respondents so that a proper

evaluation could be made upon the science based activity.

2. The steps of developing the questionnaire and the observation checklist in order to evaluate learning behavior of students with disabilities are as follows:

1.1 Study the structures and approaches in devising the observation checklist from the concepts, theories, documents, academic articles and meterials, textbooks, related researches, as well as information on the Internet.

1.2 Study learning behavior patterns of students through textbooks and academic documents and on the internet.

1.3 Develop a questionnaire and observation checklist to evaluate the learning development of students who are disabled in 3 areas such as planning stage, resilience, ability to solve problems. The students were interviewed and observed after the science based activity was fully completed. The assessment of their performance focused on the 3 topics and there were 5 score levels which includesvery good, good, fair, needs improvement and change needed.

1.4 Send the questionnaire and observation checklist to a total of 5 experts in order to check its accuracy through the use of the Index of Congruence (IOC) and the value falls in between $0.60-1.00$. 
1.5 Apply the questionnaire and observation checklist to assess the learning behavior of disabled students with the actual respondents.

\section{Data Collection}

Steps in Data Collection are as follows:

1. Using the university's media available to keep students informed of the project: science-based photo framing

2. Contact The Demonstration School of Ramkhamhaeng University to be the venue for the activity on Sundays October 4,11,18 and 25, 2015.

3. Organize the activity: science-based photo framing. The researcher trained a student to work as an assistant demonstrating the processes to 14 disabled students.

4. Collect all information and details from disabled students who participated in the science-based activity at an appointed time. The students were then interviewed and observed for general assessment. The interview was conducted by an interpreter through a sign language. And observation was made on the behavior of students with disabilities enrolled at Ramkhamhaeng University. Data and details about students' learning behavior were collected .

\section{Data Analysis}

The researcher gathered the data and analyzed the variables using a software program. The details are as follows:

1. Information on assessment of the scientific skills in developing the scientific photo frame. It was analyzed through the use of percentile and average ) $\bar{X}$ (

2. Information on the status of disabled students was analyzed by the use frequency and percentile.

3. Information on observation made on the learning behavior of disabled students by finding the percentile and average. $) \bar{X}($

\section{Conclusions}

1. In general, the students engaged in these scientific activities displayed a good level of performance. Seven of them excellently carried out their tasks while there was only one student whose performance was below the standard.

2. Overall, their learning behaviors exhibited were satisfactory. Four students displayed distinctive learning behaviors and three of them displayed unsatisfactory learning behaviors.

\section{Discussion}

The following were the research findings: 
1. Disabled students that had voluntarily participated in the science-based activity of photo framing had a favorable feedback. This was because students had participated in an activity that they wanted to eventhough the activity was science-based and might not be relevant to the current field of many of these students. However, the science-based photo framing involved the students' own photos and those close to them in the activity, making them focus and intend to learn how to work effectively. And it was also a chance for them to relax from studies in the university. This is in relation to Thorndike's theory on satisfaction (Chaiwat Suthirat, 2009, page 18-19) which concludes that when people get their gratification as expected, they want to continue to learn but if they are not satisfied with the results they might not want to continue to learn .[5]This also coincides with the research work of Onsiri Lertkittisuk (2005) who stated that independent registration for elective activities is what students want the most.[6] Participating in this activity, 7 students had performed very well. They were able to plan well, proceed to work, show expertise and they were able to adapt on what they had learned to further on other work on their own after the activity finished. Considering the problems that arose, we found that hearing impairment had low effect to the learning process to perform the activity. The students with disabilities found alternative ways to learn the activities very well. They relied upon observing the person demonstrating and followed the steps very well. This is in accordance with the theory of Classical Conditioning or Automatic Conditioning. Even though students did not communicate with the demonstrator, they could see and follow the steps in making the photo frame. We also observed that when we tried to give students to think and design for themselves; they were able to perform these and modify from the original photo that was shown in the class. This is also in relation to the research work of Suvijak Atikhomkulchai (2011) who had developed a curriculum about science projects. He discovered that students can execute science-based activities in a good level.[7] There was only 1 student who did not manage to perform very well. It may be because that student disliked the smell of resin which is an important compound in making the photo frame. Thus the student was not interested and was not able to pass the expected level. This is also in relation to Thorndike's Theory on Uses of Gratification (Chaiwat Suthirat, 2009, page 18-19) which concluded that when people are not satisfied with the results they might not want to continue to learn. [8]

2. Disabled students who voluntarily participated in the science-based activity of photo-framing, mostly have satisfactory level of learning behavior. This is probably because disabled students with disabilities on campus are faced with 2 problems that affect their studies. The first factor is the high cost of living and the second one is the lack of special assistance towards their learning. The first problem of many disabled students enrolled in Ramkhamhaeng University comes from not well-to-do background - the assistance Ramkhamhaeng University gives is waivering or fixed tuition fees, flexibility on class attendance and no debarment from exams. This is in respect to the findings of Kesinee Klinsukon (2013, Page 1) that mentioned the nature of students in Ramkhamhaeng University. They do not show up for classes and do not attend the lecture, making them not quite successful.[9] However, after disabled students participated in the science-based photo frame activity, these students were able to connect with other disabled students. They are able to locate various facilities on 
campus which leads to better resilience to problems then they would be able to solve these problems better than before. For example they can make telephone calls using sign language. They are able to find free turtorial places with the help of their friends - as they too are disabled and don't want to spend money. They also manage to find other teaching materials as recommended by their friends. This apparently helps resolve problems and is consistent with Theory of Classical Conditioning that states humans tend to perceive stimuli that are similar and respond similarly (Chaiwat Suthirat, 2009, page19-20).[10] Hence this shall help improve their learning behavior and capabilities. This coincides with the research work of Porntip Wongnapa (2005) who discovered that pilot groups of students in a scientific laboratory class displayed the ability to learn scientific process skills. And the ability to perform scientific experiments was better than when they had started.[11] This proves that scientific activities can help develop learning capabilities. The second problem for students with disabilities comes from the lack of supporting facilities for their learning. Students with hearing impairment are classified into two categories: those who are deaf and thise with partial hearing loss. Students with deafness face many problems in learning eventhough the majority of them do not work, just study. The main cause is that there are not enough interpreters available at the university. Currently there is only one interpreter who can help, making it difficult for the students with hearing disabilities. They have a hard time understanding what is taught in class and are mentally challenged to fully understand. So learning experience is negative for them. This goes accordingly with Thorndike's theory about the matter of satisfaction (Chaiwat Suthirat, 2009, page 18-19) that when there is no readiness, learning cannot be successful .[12]This also coincides with the research of Bell )Bell, 2013( who had analyzed and described teaching and learning of students with hearing impairment in the university level. He found that generally there is not enough assistance and service for hearing impaired students as of yet.[13] Ramkhamhaeng Univesity is also one of those places who face similar challenges. There have been students with disabilities who have registered for the classes but unable to come to the exams. This means the students have not successfully completed their studies. For those with partial hearing loss, they are able to gather information from the media and information boards posted in the university and are able to complete their studies well and a bit easier. For those students who are working independently and able to organize their study time and allocate time to take the exams, they will be able to complete their studies well. However, those students who work for a private firm or in an office setting usually struggle in taking time off to come to take the exams as specified by the university. Eventhough these students have prepared for the exams, they are not able to take time off from work. Then they are likely to register for the exams again. And if they are lucky, they will be able to take that particular day off from work to be excused to make it for the re-exams. This is a major obstacle for many to successfully complete their studies. Considering the students individually, 4 of them who have good learning behavior have similar characteristics as these 4 people work independently on their own. They are able to come to exams as scheduled by the university. In addition, these students can use media and information pools provided by the university to communicate so they are able to pursue the activities that the university hosts and as a result very successful in their sudies. This is in line with the research work of Rutchanee 
Phurahong (2006) stating that students who learn through a scientific framework will be able to study in a high level.[14] And the simimar matter is also suggested by the research work of Waenkaew Phanomkaen (2010) who had earlier developed a syllabus that integrated science projects. It was found out that students were interested in learning and generated a sense of satisfaction when participating in the activities.[15] These must be utilized when organizing learning activities to help the students achieve the learning objectives. Science-based activities make learning behavior change in a better way than before. For 3 students who had a lower achievement than the required standard, they have similar characters. They usually separated themselves from the group. They are not confident to work with other people and reluctant to socialize with normal students. Some need their assistants present when performing the assigned activities. This is a special characteristic of persons with hearing disabilities as stated by the research work of Erin (2009). It was stated that even though normal persons display positive facial expressions, this group of hearing impaired students usually tend to memorize negative ones.[16]This is in accordance with the research work of Nicole (2011) that studied the communication process of those with hearing impairment. It was found out that there is emotioanl differences between those who are deaf and those who have normal hearing. [17]The latter do not feel like participating in the activity so they are not very attentive and participative. This leads to unsuccessful results in the activities, both individual work and group work. Their learning behavior shows no improvement. In addition, due to their duties and responsibilities at work, they fail to show up in exmas so the result is unsatisfactory.

\section{Recommendations}

Suggestions for further usage of the research results

The university should find more interpreters who can use sign language to facilitate learning process.

For instructional audio-visual aids and videos, there should be a sign language as an option

There should be part time jobs or activities that offer some allowance so that students can have another source of income

Funds for students with hearing impairment should include expenses on hearing instruments and aids.

The science-based activities had impacted and received a lot of interests and positive feedback from students with disabilities. Then the university should provide more of such activities

There should be more studies and approaches to help improve and develop the learning behavior of those with disabilities.

2. Suggestions for further research.

1. There should be extended studies on other science based activities to help train and develop the students.

2. There should be further studies on the use of science based activities with students with other types of disabilities such as physical disabilities (arms, legs) in order for them to consider different choices of professions. 
3. There should be further studies on disabled students through the use of a variety of study tools such as a combined use of data collection tools in order to achieve better and complete information.

\section{References:}

[13]Bell, Diane.(2013). Investigating Teaching and Learning Support for Students with Hearing Impairment at A University in The Western Cape. [Online].Retrieved April,3,2014,from

file:///C:/Documents $\% 20$ and $\% 20$ Settings/Administrator/My $\% 20$ Documents/Downloads/bell investigati ng 2013.pdf

[5][8][10][12]Chaiwat Suthirat. (2009). 80 Innovations for Student-based Activities.

Bangkok: Daenext Inter-Corporation Company Limited.

[16]Erin ,Ruth Liselott Olika.)2009(. Attitudes hearing impaired children face from hearing

people. A case study from Wollega, Ethiopia. [Online]. Retrieved April,3,2014,from

https://www.duo.uio.no/bitstream/handle/10852/32268/MG_07_09_Olika.pdf?sequence=1

[4][9]Kesinee Klinsukon, Kesarin Panudom, Pornpimol Wongarun andNarupol Saelim

(2013). Without Class Attendance, How Can Ramkambaeng University Students

Graduate?. Retrieved July 17, 2015, from

http://www.oknation.net/blog/Kasi/2013/09/13/entry-1

[17]Nicole ,Brittany, Lash. (2011). Deaf or Hearing : A Hearing Impaired Individual's

Navigation between two Worlds. [Online]. Retrieved April,3,2014 from

http://uknowledge.uky.edu/cgi/viewcontent.cgi?article $=1147 \&$ context $=$ gradschool

theses

[1]Office of the Council of State (2007). An Act of Development and Improvement of the

Disabled's Quality of Life 2007. Retrieved April 20, 2011 from

http://www.kroothaiban.com/news-id4768.html

[3] Office of the Higher Education Commission (2011). Human Resource Development

Program on Teaching and Learning Approaches for Disabled Students at Collegial

Level: Additional Services and Support for the Disabled During the Transitional

Period From High School to College: Workshop Materials. Bangkok: Office of the

Higher Education Commission.

[6]Onsiri Lertkittisuk. (2003).V ocational project management in the secondary schools under

the office of basic education commission. Thesis: M.Ed.Educational Technology,

Burapha University.

[11]Porntip Wongnapa. (2005). A Development of science laboratory directions on extraction

and isolation of Xanthones from mangosteen fruits for twelfth grade students in

Chanthaburi province. Thesis: M.Ed. Science Education, Srinakharinwirot University.

[14]Rutchanee Phurahong. (2003). A study of learning achievement and scientific process

skill on the medicinal herb of prathomsuksa 6 students using science project. Thesis:

M.Ed. Curriculum and Instruction, Thepsatri Rajabhat University.

[2]Srisuk Sujirakul. (2008). The Meeting of Basic Needs in Educational Programs for

Physically Challenged Students at Ramkhambaeng University. Research Project,

Student Affairs, Office of the President, Ramkhamhaeng University.

[7]Suvijak Atikhomkulchai. (2011).The development of selective courses on science project

in local product for sixth grade students. Thesis: M.Ed. Curriculum and Instruction,

Silpakron University.

[15]Waenkaew Phanomkaen.(2011). The Devolvenment of learning activity plans in chemistry entitle: rate of chemical meaction by integration with science project on bangfaitalai. Thesis: M.Ed. Science Education Chemistry), Rajabhatmahasarakham University. 